Managers may consider further reduction in already precarious nursing levels.

Although video monitoring is non-invasive it raises a number of ethical issues (Leong \& Silva, 1989). Is there a need for acquiring formal consent from the patient to allow observation through the video camera? Need the multidisciplinary staff give their formal consent as well? The other ethical issue is the invasion of the patient's privacy. There need be no formal video recording, this instrument should purely be used for 'here and now' observations.

Video monitoring of dangerous behaviours (Brizer et al, 1988) is a novel idea and its advantages and disadvantages require formal prospective evaluation, including analysis of cost-effectiveness. Information needs to be collected from patients, relatives, members of the multi-disciplinary team, patient advocacy groups and the Mental Health Act Commission regarding their views on this topic.

Brizer, D. A., Crowner, M. L., Convit, A., et al (1988) Videotape recordings of inpatient assaults: a pilot study. American Journal of Psychiatry, 145, 751-752.

LeonG, G. B. \& SilvA. J. A. (1989) Videotape recordings of assaultive inpatients. American Journal of Psychiatry. 146, 287.

Shah A. K. \& Ganesvaran, T. (1993) Can videos be used to monitor psychiatric inpatients? Australasian Psychiatry. 1, 158-159.

DEEPA DIGHE-DEO, Specialist Registrar, Department of Old Age Psychiatry, West Middlesex University Hospital, Isleworth and AJIT SHAH, Senior Lecturer in Psychiatry of Old Age, Imperial College of Science, Technology and Medicine, London

\section{The dispensable psychiatrist}

Sir: How slowly psychiatrists change. Dr John Kellett (Psychiatric Bulletin, September 1997, 21. 581-582) describes something of the uncertainty that evidently still prevails regarding the new style of psychiatry, quite aside from the pressing problems currently facing the profession.

I have argued (Bennet, 1988) that with the various health professionals becoming increasingly skilled in therapeutic techniques, the psychiatrists should (a) take advantage of their broad basic training which enables them, if they wish, to comprehend everyone else's work in the mental health team, and (b) develop their specific skills and knowledge, which are medical. Members of a multi-disciplinary team share skills, which they use much, or most, of the time. Each, in addition, has specific skills deriving from their basic training: the psychiatrist's is medicine.
I am now more of a spectator of the scene than a participant and I find psychiatrists are often less fulfilled now than they were ten years ago. I wonder how many have really tried to move with the times. It can be genuinely hard for some to conceptualise mental disorders except in terms of diseases, so they perambulate the well-known paths, while other mental health professionals are moving ahead.

The range of therapeutic measures employed by these professionals is increasing, and they cost less to employ than doctors. They are also usually much more open about themselves and have taken the trouble to learn about the various influences on them which have brought them to be the people that they are-influences which they take for granted will underpin and colour the way that they work, and possibly in an adverse way if they are not conscious of them.

Such self-scrutiny is taken as a sine qua non for most therapists, but the majority of psychiatrists, probably because of the biological bias of British psychiatry, do not feel that it is necessary to look at themselves. Thus many psychiatrists appear to their non-medical colleagues as hopelessly naive as individuals and lacking the psychological strength to carry the burden of emotionally needy people, without resorting to medication and their traditional sanctions.

As the nineties are coming to their end, the request with which I ended my British Medical Journal paper still seems to apply:"Keep up with your general medicine and be more open about yourselves". Can someone tell me if anything really has changed?

BENNET, G. (1988) What should psychiatrists be doing in the 1990s? British Medical Joumal, 296, 274-275.

GLIN BENNET, Formerly Consultant Senior Lecturer, Department of Mental Health. University of Bristol, and Consultant Psychiatrist, United Bristol Hospitals NHS Trust, Bristol

\section{Tardive dyskinesia}

Sir: We wish to comment on the descriptive review article on the treatment of tardive dyskinesia (TD) by Duncan et al (Psychiatric Bulletin, July 1997, 21, 422-425), and bring to the readers' attention the systematic reviews already published in the Cochrane Library (htpp://archie.cochrane.co.uk/info/abstracts/ abidx.htm\#G06@). One hundred and fourteen different types of interventions were used in $\mathbf{3 6 0}$ clinical trials over the past $\mathbf{4 0}$ years (Soares et al, 1996). Seventy clinical trials were included in at least one of the systematic reviews. The others were excluded because they were either not 